KANSAS JOURNAL of MEDICINE

\section{Associations between Fall Distance, Age, and Trauma Outcomes in Older Adult Patients}

Gina M. Berg, Ph.D., MBA', ${ }^{1,2}$, Ashley M. Hervey, M.Ed. ${ }^{1}$,

Felecia A. Lee, Ph.D. ${ }^{1}$, Sarah Holmes, PA-C ${ }^{3}$,

Kayla R. Keuter, PA-C, MPH, M.A. ${ }^{3}$, Paul B. Harrison, M.D. ${ }^{2}$

${ }^{1}$ University of Kansas School of Medicine-Wichita,

Department of Family and Community Medicine, Wichita, KS

${ }^{2}$ Wesley Medical Center, Trauma Services, Wichita, KS

${ }^{3}$ Wichita State University, Department of Physician Assistant, Wichita, KS

\section{ABSTRACT}

Introduction. Falls are the leading cause of injury death among older adults. This study sought to determine if there are differences between fall distance (ground level vs greater than ground level) and age (old vs very old) in terms of in-hospital mortality, orthopedic consultations, and neurological consultations.

Methods. A retrospective trauma registry review was conducted of older adult patients (aged $>65$ years), admitted to a Midwestern Level I trauma facility (2005 - 2010) due to a fall.

Results. Of the 1,064 patients analyzed, the majority fell from ground level compared to greater than ground level (64\% and $36 \%$, respectively). Median age was 80 years. Fall distance was not associated significantly with in-hospital mortality (OR 0.88; CI 0.50 - 1.54) or neurological consultations (OR 1.02; CI $0.72-1.43)$, but was associated with orthopedic consultations (OR 1.49; CI 1.09 - 2.04). Age was not associated with in-hospital mortality or neurological or orthopedic consultations.

Conclusions. Fall distance was not associated with in-hospital mortality or receiving a neurological consultation. However, older adults who fell from greater than ground level were more likely to receive orthopedic consultations. There were no differences in in-hospital mortality or receiving a neurological or orthopedic consultation based on age. These findings indicated that as the older adult population increases, burden of care will increase for trauma centers and neurological services. KS J Med 2016;9(3):54-57.

\section{INTRODUCTION}

By the year 2040, older adults will comprise approximately $22 \%$ of the U.S. population. ${ }^{1}$ Falls are the leading cause of fatal injuries among the older adult population, affecting one in three aged 65 years or older and half of those aged 80 years or older. ${ }^{2}$ Despite the low-energy mechanism, falls from ground level can result in disproportionate injury and potentially death in older adults. ${ }^{3}$ Spaniolas et al. ${ }^{4}$ noted a significant increase in incidence of severely injured older adult patients with those 69 years and younger $(11.5 \%$ vs $9 \%$; $<<0.0001)$.

Compared to younger counterparts, older patients sustain severe injury more frequently and die more often following trauma, due to reduced physiological reserve, underlying comorbidities, and ensuing complications. ${ }^{5,6}$ In addition to higher mortality rates, older adults who suffer a traumatic event have prolonged hospitalization and consume a disproportionate amount of resources. ${ }^{7}$ McKevitt et al. ${ }^{8}$ found when using resource requirements as measured by length of stay and number of consults, older adults have greater use per admission than younger patients with similar injury severity. After suffering a fall, $20-30 \%$ of older adults will experience a moderate to severe injury, including fractures and head traumas, often requiring orthopedic and neurological consultations. ${ }^{9}$

As the population ages and older adults become larger consumers of trauma care, the available resources may not support the growing need of geriatric specific trauma services adequately. Currently, there is a lack of data describing the utilization of trauma resources in the older adult population, specifically neurological and orthopedic consultations in terms of fall-related injuries. Therefore, we sought to determine if, in older adult trauma patients, there were differences between fall distance and age in terms of in-hospital mortality, orthopedic consultations, and neurological consultations.

\section{METHODS}

This was a retrospective trauma registry review of older adult patients (aged $>65$ years) identified as sustaining an injury due to a fall, admitted to a Midwestern Level I trauma facility in a predominately rural state between January 1, 2005 and December 31, 2010. Patients who were dead on arrival, burn victims, and those transferred to another acute care facility within one week were excluded as their final outcomes are not present in the registry. A total of 635 patients with missing Injury Severity Score (ISS) and hospital Glasgow Coma Scale (GCS) also were excluded from analysis. Approval for this study was obtained from all relevant institutional review boards.

Study variables. Demographic and clinical data extracted from the trauma registry included age, gender, race, ISS, hospital GCS, injury location, fall distance, medical consultations, hospital and intensive care unit (ICU) length of stay (LOS), physiological complications (e.g., pulmonary, cardiovascular), procedures, hospital disposition (excluding deceased), and in-hospital mortality. For comparison, patients were divided into age categories defined as old (aged 65 - 79 years) and very old (aged $>80$ years) based on the median age of 80 years. Fall distance was defined as ground level (GL: i.e., standing, slipping, tripping) and greater than ground level (> GL: e.g., stairs, ladder, or one level to another). Outcome variables were defined as in-hospital mortality, orthopedic consultations, and neurological consultations.

Statistical analysis. Descriptive statistics were summarized using frequencies (percentages) and medians (range). Differences in study variables were compared according to fall distance and age 


\section{KANSAS JOURNAL of MEDICINE}

FALL DISTANCE AND OLDER ADULT PATIENTS continued.

and evaluated by chi-square statistics and Mann-Whitney U tests due to the inability to meet parametric distribution assumptions. Logistic regression analyses were used to analyze outcome differences based on fall distance and age. Medical factors known to be associated with trauma outcomes (age, gender, and ISS) ${ }^{10,11}$ were controlled in these analyses in addition to hospital GCS, ICU and hospital LOS, and physiological complications with in-hospital mortality, orthopedic consultations, and neurological consultations as outcome variables. Statistical significance was defined as $\mathrm{p}<0.05$. Adjusted odds ratio (AOR) and $95 \%$ confidence intervals (CI) are reported. Statistical analyses were performed using SPSS for Windows, Version 20.0 (IBM, Armonk, NY).

\section{RESULTS}

Of the 1,064 patients in the final sample, the median age of the entire population was 80 years (Table 1). GL falls were more common than > GL falls (64\% and 36\%, respectively).

Fall distance: Univariate analysis. Falls $>$ GL had significantly higher median ISS compared to GL (10 vs 9; $p=0.019)$. No significant differences were observed in hospital GCS $(p=0.262)$ or injury locations between GL and > GL falls (Table 1). There were also no observed differences in the median number of physiological complications $(p=0.224)$. No differences were identified in ICU LOS ( $p=0.394)$ or hospital LOS ( $p=0.950)$. Differences were found in orthopedic consultations $(p=0.033)$, but not neurological consultations $(p=0.338)$. Falls $>$ GL were more likely to receive an orthopedic consult. There was no significant difference in in-hospital mortality between GL and > GL falls ( $p=0.669)$.

Age: Univariate analysis. Neither ISS nor hospital GCS were significantly different between the old and very old (Table 2). The only significantly different injury locations between old and very old were external $(7.7 \%$ vs $11.4 \%$; $<0.05)$ and extremities $(14.6 \%$ vs $17.9 \%$; $<0.05)$, respectively. There also were no observed differences in the median number of physiological complications $(p=0.252)$. Differences were identified in ICU LOS (0 [0-41] vs 0 [0-18] days; $p=0.011)$, but not hospital LOS $(p=0.607)$. Differences were not found in orthopedic consultations $(p=0.980)$ or neurological consultations $(p=0.183)$. There was no significant difference in inhospital mortality between the old and very old $(p=0.764)$.
Table 1. Demographics and outcomes based on fall distance. ${ }^{a}$

\begin{tabular}{|c|c|c|c|c|}
\hline & $\begin{array}{l}\text { Total } \\
1064\end{array}$ & $\begin{array}{c}\text { Ground } \\
\text { Level } \\
681(64.0)\end{array}$ & $\begin{array}{c}>\text { Ground } \\
\text { Level } \\
383(36.0)\end{array}$ & $\mathbf{p}$ \\
\hline $\begin{array}{l}\text { Age (median, } \\
\text { range) }\end{array}$ & $80(65-103)$ & $82(65-101)$ & $78(65-103)$ & $<0.001$ \\
\hline $\begin{array}{l}\text { ISS (median, } \\
\text { range) }\end{array}$ & $9(1-42)$ & $9(1-42)$ & $10(1-41)$ & 0.019 \\
\hline $\begin{array}{l}\text { Hospital GCS } \\
\text { (median, range) }\end{array}$ & $15(3-15)$ & $15(3-15)$ & $15(3-15)$ & 0.262 \\
\hline $\begin{array}{l}\text { ICU LOS } \\
\text { (excludes deceased; } \\
\text { median, range) }\end{array}$ & $0(0-41)$ & $0(0-19)$ & $0(0-41)$ & 0.394 \\
\hline $\begin{array}{l}\text { Hospital LOS } \\
\text { (excludes deceased; } \\
\text { median, range) }\end{array}$ & $3(1-43)$ & $3(1-35)$ & $3(1-43)$ & 0.950 \\
\hline $\begin{array}{l}\text { Physiological } \\
\text { Complication } \\
\text { (median, range) }\end{array}$ & $0(0-7)$ & $0(0-6)$ & $0(0-7)$ & 0.224 \\
\hline Age & & & & $<0.001$ \\
\hline $65-79$ & $493(46.3)$ & $276(40.5)$ & $217(56.7)$ & \\
\hline$>80$ & $571(53.7)$ & $405(59.5)$ & $166(43.3)$ & \\
\hline Gender & & & & $<0.001$ \\
\hline Female & $611(57.4)$ & $420(61.7)$ & $191(49.9)$ & \\
\hline Race & & & & 0.340 \\
\hline White & $1046(98.4)$ & $671(98.7)$ & $375(97.9)$ & \\
\hline \multicolumn{5}{|l|}{ Injury Location } \\
\hline Abdominal & $27(2.5)$ & $16(2.3)$ & $11(2.9)$ & 0.603 \\
\hline Chest & $50(4.7)$ & $31(4.6)$ & $19(5.0)$ & 0.762 \\
\hline $\begin{array}{r}\text { External } \\
\text { (skin and thermal) }\end{array}$ & $103(9.7)$ & $67(9.8)$ & $36(9.4)$ & 0.849 \\
\hline $\begin{array}{r}\text { Extremities } \\
\text { (including pelvis) }\end{array}$ & $174(16.4)$ & $17(17.2)$ & $57(14.9)$ & 0.552 \\
\hline Face & $43(4.0)$ & $27(4.0)$ & $16(4.2)$ & 0.866 \\
\hline Head or neck & $357(33.6)$ & $234(34.4)$ & $123(32.1)$ & 0.456 \\
\hline $\begin{array}{l}\text { Neurological } \\
\text { Consultation }\end{array}$ & $471(44.3)$ & $294(43.2)$ & $177(46.2)$ & 0.338 \\
\hline $\begin{array}{l}\text { Orthopedic } \\
\text { Consultation }\end{array}$ & $268(25.2)$ & $157(23.1)$ & $111(29.0)$ & 0.033 \\
\hline $\begin{array}{l}\text { Home } \\
\text { Disposition }^{b} \\
\text { (excludes deceased) }\end{array}$ & & & & 0.461 \\
\hline Home & $549(56.5)$ & $349(55.9)$ & $200(57.5)$ & \\
\hline Continued Care & $405(41.7)$ & $261(41.8)$ & $144(35.6)$ & \\
\hline Non-Home & $18(1.9)$ & $14(2.2)$ & $4(22.2)$ & \\
\hline Mortality & & & & 0.669 \\
\hline Deceased & $92(8.6)$ & $57(8.4)$ & $35(9.1)$ & \\
\hline Survived & $972(91.4)$ & $624(91.6)$ & $348(90.9)$ & \\
\hline
\end{tabular}

Abbreviations: GCS: Glasgow Coma Score; ICU: intensive care unit; ISS: Injury Severity Score; LOS: length of stay.

aPercentages may not add to 100 due to incomplete or missing data; data presented as frequency (\%) unless otherwise specified. Mann Whitney U test completed for means testing. Chi-square test of association completed for frequency analysis. Bolded numbers denote statistical significance. bHome: home and home with health care; Continued Care: hospice, nursing home, other acute care facility, rehabilitation, skilled nursing, specialty hospital; Non-Home: mental health facility, other. 
KANSAS JOURNAL of MEDICINE

FALL DISTANCE AND OLDER ADULT PATIENTS continued.

Table 2. Demographics and outcomes based on age. ${ }^{a}$

\begin{tabular}{|c|c|c|c|}
\hline & $\begin{array}{c}\text { Ages } 65-79 \\
493(46.3)\end{array}$ & $\begin{array}{l}\text { Age } \geq 80 \\
571(53.7)\end{array}$ & p \\
\hline ISS (median, range) & $9(1-42)$ & $9(1-35)$ & 0.550 \\
\hline Hospital GCS (median, range) & $15(3-15)$ & $15(3-15)$ & 0.293 \\
\hline $\begin{array}{l}\text { ICU LOS } \\
\text { (excludes deceased; median, range) }\end{array}$ & $0(0-41)$ & $0(0-18)$ & 0.011 \\
\hline $\begin{array}{l}\text { Hospital LOS } \\
\text { (excludes deceased; median, range) }\end{array}$ & $3(1-43)$ & $3(1-25)$ & 0.607 \\
\hline $\begin{array}{l}\text { Physiological Complica- } \\
\text { tion (median, range) }\end{array}$ & $0(0-7)$ & $0(0-5)$ & 0.252 \\
\hline Gender & & & 0.001 \\
\hline Female & $256(51.9)$ & $355(62.2)$ & \\
\hline Race & & & 0.127 \\
\hline White & $482(97.8)$ & $564(53.9)$ & \\
\hline Fall Distance & & & $<0.001$ \\
\hline Ground Level & $276(56.0)$ & $405(70.9)$ & \\
\hline$\geq$ Ground Level & $217(44.0)$ & $166(29.1)$ & \\
\hline \multicolumn{4}{|l|}{ Injury Location } \\
\hline Abdominal & $17(3.4)$ & $10(1.8)$ & 0.079 \\
\hline Chest & $22(4.5)$ & $28(4.9)$ & 0.735 \\
\hline External (skin and thermal) & $38(7.7)$ & $65(11.4)$ & 0.012 \\
\hline Extremities (including pelvis) & $72(14.6)$ & $102(17.9)$ & 0.033 \\
\hline Face & $25(5.1)$ & $18(3.2)$ & 0.113 \\
\hline Head or neck & $160(32.5)$ & $197(34.5)$ & 0.481 \\
\hline Neurological Consultation & $229(46.5)$ & $242(42.4)$ & 0.183 \\
\hline Orthopedic Consultation & $124(25.2)$ & $144(25.2)$ & 0.980 \\
\hline \multicolumn{4}{|l|}{$\begin{array}{l}\text { Home Disposition } \\
\text { (excludes deceased) }\end{array}$} \\
\hline Home & $290(64.6)$ & $259(49.5)$ & $<0.001$ \\
\hline Continued Care & $154(34.3)$ & $251(48.0)$ & \\
\hline Non-Home & $5(1.1)$ & $13(2.5)$ & \\
\hline Mortality & & & 0.764 \\
\hline Deceased & $44(8.9)$ & $48(8.4)$ & \\
\hline Survived & 449 (91.1) & 523 (91.6) & \\
\hline
\end{tabular}

Abbreviations: GCS: Glasgow coma score; ICU: intensive care unit; ISS: Injury Severity Score; LOS: length of stay.

aPercentages may not add to 100 due to incomplete or missing data; data presented as frequency (\%) unless otherwise specified. Mann Whitney U test completed for means testing. Chi-square test of association completed for frequency analysis. Bolded numbers denote statistical significance.

bHome: home and home with health care; Continued Care: hospice, nursing home, other acute care facility, rehabilitation, skilled nursing, specialty hospital; Non-Home: mental health facility, other.

Multivariable analysis. Logistic regression analyses were completed to determine if fall distance was associated with in-hospital mortality, orthopedic consultations, and neurological consultations (Table 3). Fall distance was not associated significantly with in-hospital mortality (OR 0.88; CI 0.50 - 1.54) or neurological consultations (OR 1.02; CI 0.72 - 1.43), but was associated with orthopedic consultations (OR 1.49; CI
$1.09-2.04)$. Age was not associated with in-hospital mortality (OR 1.02; CI 0.98 - 1.06), neurological consultations (OR 0.98; CI 0.96 - 1.00), or orthopedic consultations (OR 1.00; CI 0.98 - 1.02).

Table 3. Logistic regression. ${ }^{a}$

\begin{tabular}{|c|c|c|c|}
\hline & Mortality & $\begin{array}{c}\text { Neurological } \\
\text { Consult }\end{array}$ & $\begin{array}{c}\text { Orthopedic } \\
\text { Consult }\end{array}$ \\
\hline & $\underset{95 \% \text { CI }}{\text { Adjusted }}$ OR & $\underset{95 \% \mathrm{CI}}{\text { Adjusted }} \mathrm{OR}$ & $\underset{95 \% \text { CI }}{\text { Adjusted }}$ OR \\
\hline Age & $1.02(0.98-1.06)$ & $\begin{array}{c}0.98(0.96- \\
1.00)\end{array}$ & $\begin{array}{c}1.00(0.98- \\
1.02)\end{array}$ \\
\hline Fall Distance & $0.88(0.50-1.54)$ & $\begin{array}{c}1.02(0.72- \\
1.43)\end{array}$ & $\begin{array}{l}1.49(1.09- \\
2.04)\end{array}$ \\
\hline Gender & $1.91(1.10-3.3)$ & $\begin{array}{c}1.03(0.74- \\
1.44)\end{array}$ & $\begin{array}{c}2.15(1.56- \\
2.96)\end{array}$ \\
\hline $\begin{array}{l}\text { Injury Severity } \\
\text { Score }\end{array}$ & $3.14(1.56-6.33)$ & $\begin{array}{c}13.65(8.99- \\
20.72)\end{array}$ & $\begin{array}{c}0.93(0.63- \\
1.38)\end{array}$ \\
\hline \multicolumn{4}{|l|}{ Hospital GCS ${ }^{b}$} \\
\hline Severe & $\begin{array}{c}9.22(4.86- \\
17.49)\end{array}$ & $\begin{array}{c}0.93(0.46- \\
1.88)\end{array}$ & $\begin{array}{l}3.65(2.12- \\
\quad 6.27)\end{array}$ \\
\hline Moderate & $3.53(1.55-8.05)$ & $\begin{array}{c}0.36(0.17- \\
0.76)\end{array}$ & $\begin{array}{l}0.71(0.32- \\
1.55)\end{array}$ \\
\hline \multicolumn{4}{|l|}{ Hospital LOSc } \\
\hline 1 day or less & $\begin{array}{c}21.51(7.55- \\
61.32)\end{array}$ & $\begin{array}{c}0.66(0.38- \\
1.13)\end{array}$ & $\begin{array}{c}0.16(0.09- \\
0.26)\end{array}$ \\
\hline 2 - 3 days & $\begin{array}{c}5.72(2.37- \\
13.80)\end{array}$ & $\begin{array}{l}2.11(1.29- \\
3.46)\end{array}$ & $\begin{array}{c}0.33(0.21- \\
0.51)\end{array}$ \\
\hline 4 - 6 days & $3.08(1.31-7.25)$ & $\begin{array}{c}1.32(0.80- \\
2.18)\end{array}$ & $\begin{array}{c}0.61(0.40- \\
0.92)\end{array}$ \\
\hline ICU LOS & $\begin{array}{c}6.35(2.73- \\
14.79)\end{array}$ & $\begin{array}{c}3.17(2.13- \\
\quad 4.71)\end{array}$ & $\begin{array}{c}0.61(0.41- \\
0.92)\end{array}$ \\
\hline $\begin{array}{l}\text { Physiological } \\
\text { Complication } \\
\text { Count }\end{array}$ & $5.6(2.81-11.16)$ & $\begin{array}{c}0.89(0.54- \\
1.49)\end{array}$ & $\begin{array}{c}1.26(0.82- \\
1.94)\end{array}$ \\
\hline
\end{tabular}

Abbreviations: CI: Confidence Interval; OR: odds ratio

aAdjusted for gender, injury severity score, hospital GCS, hospital LOS, ICU LOS and physiological complications. Bolded numbers denote statistical significance.

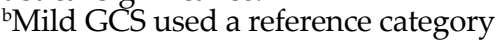

'Seven (7) days or more used as reference category

\section{DISCUSSION}

This study sought to determine if there were differences in in-hospital mortality, orthopedic consultations, and neurological consultations based on distance fallen and age. Fall distance was not associated with in-hospital mortality or receiving a neurological consultation. Fall distance was associated with receiving an orthopedic consultation. Odds of receiving an orthopedic consultation was $49 \%$ higher for those who fell from > GL compared to those who fell from GL. However, there were no differences in injury location between older adults who fell from GL or $>$ GL. Age was not associated with in-hospital mortality, neurological consultations, or orthopedic consultations.

These findings are similar to a study completed by Gelbard et al. ${ }^{12}$ who determined there were no significant differences in mortality between non-ground level falls and ground level falls in adults aged 65 years and older. However, when reviewing low velocity falls, Bergeron et al. ${ }^{13}$ determined length of stay $(\mathrm{p}<0.001)$ and mortality $(\mathrm{p}<0.001)$ were significantly higher in the elderly (aged $>65$ years) compared to the non-elderly. 
KANSAS JOURNAL of MEDICINE

FALL DISTANCE AND OLDER ADULT PATIENTS continued

Thus, regardless of the distance fallen, age should be an indicator for poorer outcomes due to reduced physiological reserve, comorbidities, and complications.,

With the growing older adult population, significant strain on resources can affect care. This population shift may result in a higher mortality rate due to an increase in falls as a mechanism of injury. ${ }^{14}$ This injured population represents a subset of trauma patients that will place a significant strain on resources and present additional challenges to optimal care. ${ }^{15}$ Fallon et al. ${ }^{15}$ described the use of a geriatric trauma team which mandates a consult from a group of geriatricians with education and skills in caring for older adults. These specialized care "units" may be necessary in the future to provide appropriate care for older adults. Effective trauma program management of the elderly trauma patient and allocation of resources depend on an understanding of the mechanisms leading to injuries in these cases.

Limitations. The trauma registry is not designed specifically for research purposes. Conclusions drawn from results are specific to a level I trauma center in a predominately rural state and may not generalize to other trauma populations. Additionally, patient characteristics (e.g., comorbidities) which may influence outcomes following falls were not included due to the incomplete nature of the variable.

Future research. Research on falls is limited because of the inability to measure distance fallen directly. ${ }^{16}$ Future research should focus on prospective multicenter studies examining factors surrounding falls and explore the interactions between fall distance and age. This is the first step in developing specific protocols in the management of older adult trauma patients, both facility specific and triage guidelines. Further, since the majority of falls are from ground level, fall prevention outreach education coordinated by trauma programs should emphasize strategies to prevent GL falls, with the expectation to reduce fall-related injuries, comorbidities, death, and burden on the health care system. Given the high rate of mortality $(8.6 \%)$ in this population compared to previous literature utilizing the National Trauma Databank, ${ }^{4}$ future research should evaluate mortality trends in older adults who have suffered a fall.

\section{CONCLUSION}

Fall distance (GL vs > GL) was not a predictor of in-hospital mortality or likelihood of receiving a neurological consultation in the older adult trauma population. However, older adults who fell from > GL were more likely to receive orthopedic consults. Older adults who fall from GL have similar outcomes compared to those who fall from > GL. Similarly, very old (aged $>80$ years) patients have similar outcomes compared to the old (aged 65 - 79 years). There were no differences identified in in-hospital mortality, receiving an orthopedic consultations, or neurological consultation based on age.
As the older adult population increases, patient care burden also will increase for trauma centers and neurological services. A better understanding of the population and the mechanisms leading to injuries will aid in the management of the elderly trauma patient and appropriate allocation of resources.

\section{REFERENCES}

${ }^{1}$ Administration on Aging. Aging statistics. http:// www.aoa.gov/Aging_Statistics/. Accessed June 14, 2016. ${ }^{2}$ Chisholm KM, Harruff RC. Elderly deaths due to ground-level falls. Am J Forensic Med Pathol 2010; 31(4):350-354. PMID: 20938326. ${ }^{3}$ Sterling DA, O'Connor JA, Bonadies J. Geriatric falls: Injury severity is high and disproportionate to mechanism. J Trauma 2001; 50(1):116-119. PMID: 11231681. ${ }^{4}$ Spaniolas K, Cheng JD, Gestring ML, Sangosanya A, Stassen NA, Bankey PE. Ground level falls are associated with significant mortality in elderly patients. J Trauma 2010; 69(4):821-825. PMID: 20938268. ${ }^{5}$ Blumenthal J, Plummer E, Gambert SR. Trauma in the elderly: Causes and prevention. Clin Geriatr 2010; 18:21-24. ${ }^{6}$ Aschkenasy MT, Rothenhaus TC. Trauma and falls in the elderly. Emerg Med Clin North Am 2006; 24(2):413-432. PMID: 16584964. ${ }^{7}$ MacKenzie EJ, Morris JA Jr, Smith GS, Fahey M. Acute hospital costs of trauma in the United States: Implications for regionalized systems of care. J Trauma 1990; 30(9):1096-1103. PMID: 2213943. ${ }^{8}$ McKevitt EC, Calvert E, Ng A, et al. Geriatric trauma: Resource use and patient outcomes. Can J Surg 2003; 46(3):211-215. PMID: 12812248.

${ }_{9}$ World Health Organization. Falls: FactSheet.October 2012.http://www. who.int/mediacentre/factsheets/fs344/en/. Accessed March 15, 2016. ${ }^{10}$ Haider AH, Chang DC, Efron DT, Haut ER, Crandall M, Cornwell EE 3rd. Race and insurance status as risk factors for trauma mortality. Arch Surg 2008; 143(10):945-949. PMID: 18936372. ${ }_{11}$ Heffernan DS, Vera RM, Monaghan SF, et al. Impact of socioethnic factors on outcomes following traumatic brain injury. J Trauma 2011; 70(3):527-534. PMID: 21610339. ${ }^{12}$ Gelbard R, Inaba K, Okoye OT, et al. Falls in the elderly: A modern look at an old problem. Am J Surg 2014; 208(2):249-253. PMID: 24814307.

${ }_{13}$ Bergeron E, Clement J, Lavoie A, et al. A simple fall in the elderly: Not so simple. J Trauma 2006; 60(2):268-273. PMID: 16508481. ${ }_{14}$ Allen CJ, Hannay WM, Murray CR, et al. Causes of death differ between elderly and adult falls. J Trauma Acute Care Surg 2015; 79(4):617-621. PMID: 26402536. ${ }^{15}$ Fallon WF Jr, Rader E, Zyzanski S, et al. Geriatric outcomes are improved by a geriatric trauma consultation service. J Trauma 2006; 61(5):1040-1046. PMID: 17099506. ${ }^{16}$ Sasser SM, Hunt RC, Faul M, et al. Guidelines for field triage of injured patients: Recommendations of the National Expert Panel on Field Triage, 2011. MMWR Recomm Rep 2012; 61(RR-1):1-20. PMID: 22237112.

Keywords: falls, aged, mortality, referral and consultation 